\title{
GEOGRAPHICAL ASSESSMENT OF FACTORS FOR SASA EXPANSION IN THE SAROBETSU MIRE, JAPAN
}

\author{
MASAYUKI TAKADA*, TAKASHI INOUE**, YOSHIO MISHIMA**, HIROKO \\ FUJITA***, TAKASHI HIRANO**, YOSHIYASU FUJIMURA***
}

\begin{abstract}
*Hosei University, 2-17-1, Fujimi, Chiyoda-ku, Tokyo 102-8160, Japan, e-mail: mtakada@hosei.ac.jp

**Hokkaido University, Graduate School of Agriculture, North 9, West 9, Kita-ku, Sapporo 060-8589, Japan

***Hokkaido University, Botanic Garden, Field Science Centre for Northern Biosphere, North 3, West 8, Chuo-ku, Sapporo 060-0003, Japan
\end{abstract}

Received: $30^{\text {th }}$ August 2010, Accepted: $15^{\text {th }}$ February 2012

\begin{abstract}
To determine the factors that promote the expansion of dwarf bamboo (Sasa palmate), an indicator of mesic vegetation, into bogs, a landscape-based approach was used to assess the geographical factors that are associated with, and contribute to, the propagation of Sasa in the Sarobetsu Mire, northern Japan. Using the "Sasa frontline" data obtained from aerial photographs taken during 2 different periods, the area expanded by Sasa in the past 23 years was determined. Next, distribution maps associated with geographical parameters, such as topography, hydrology, vegetation and soil, were created using remote sensing data (airborne LiDAR, ALOS/AVNIR-2, and ALOS/PALSAR). Using these geographical parameters as explanatory variables, the causes for Sasa expansion were analyzed by multiple linear regression analysis. It was shown that distance to natural ditches, gradient of ground surface, elevation, and carbon content are the largest contributors and that the hydrological factor is the one most associated with Sasa expansion. By using the landscape approach, $60 \%$ of the Sasa expansion factors could be explained. The analysis of the vegetation near the Sasa frontlines showed that the dynamics of sedge vegetation may serve as an indicator of potential Sasa expansion.
\end{abstract}

Keyword: mire, dwarf bamboo, Sasa expansion, geographical parameter, remote sensing

\section{INTRODUCTION}

Wetlands/peatlands are unique ecosystems that form under specific environmental conditions, whereby high precipitation, and low temperatures result in low evaporation and waterlogged soils. Within these soils, plant decomposition is suppressed by anaerobic and acidic conditions. Together, wetlands and peatlands account for approximately 3\% of Japan's total terrestrial area (Pfadenhauer et al. 1993). In addition to their role in local climate and flood control, they serve as habitats for valuable wildlife, playing an important role in biodiversity conservation; many wetlands are currently under protection. Furthermore, the amount of carbon sequestered in wetland peat soil is said to be equivalent 
to the carbon content of all terrestrial plants. In recent years, the role of wetlands as a carbon sink has been under the spotlight in the climate change issue (Gorham 1991; Maltby and Immirzi 1993).

Wetlands, however, are subjected to environmental changes. In particular, ombrotrophic bogs are vulnerable to vegetation changes caused by human impact or natural factors. Moreover, invasion of mesic (non-wetland) vegetation is a serious threat to bogs because it causes degradation of wetland ecosystems and their biodiversity (Hobbs and Humphries 1995).

Identifying the current status of, and factors for, vegetation change is necessary to determine how effective control or restoration measures may be undertaken to preserve the bogs from expansion of mesic vegetation. The factors that cause vegetation change include biological, physical, and chemical factors, which are interrelated, and often encompass a wide range of scale from the microenvironment to an ecosystem, such as a wetland. This prevents the efficient development and implementation of measures for managing mesic conditions within bogs. To date, many studies on plant invasion have concentrated on the control of individual species or have analyzed limited geographical areas. The results of these studies are not always satisfactory (Hobbs and Humphries 1995).

Kellner and Halldin (2002) and Petrone et al. (2004) confirmed the need to identify the spatial distribution of environmental factors for an entire target area, to ensure adequate conservation and management of wetlands, whilst Rydin and Jeglum (2006) stated the importance of large-scale conservation approaches. Hobbs and Humphries (1995) found that the spatial and temporal dynamics of the expansion of invading populations is an important component for plant invasions.

In this study, we analyzed the causes for the expansion of dwarf bamboo (Sasa palmata), an indicator of mesic vegetation in contrast to moist environments, into bogs by using a landscape approach. To develop effective management strategies, we assessed the geographical factors that are associated with, and contribute to, changes in wetland vegetation from a landscape perspective.

Sasa sp. belong to family Poaceae and are distributed throughout Far East Asia, particularly in China, Korea, Japan, and Sakhalin. They mainly propagate by means of horizontal rhizomal growth. In Japan, Sasa sp. are widely distributed from lowland to alpine areas, and occasionally, they form dense communities in the grasslands and forest understoreys; this interferes with the regeneration of other plants (Narukawa and Yamamoto 2002; Ito and Hino 2007; Suyama et al. 2000). In the wetlands of Japan, dwarf bamboo is an indication of mesic conditions. In many of these lowland wetland areas, because of the creation of agricultural drainage ditches in the surrounding areas, groundwater levels have decreased. This has led to the expansion of dwarf bamboo, which has become a problem (Fujita 2007)."

\section{METHODS}

\section{Study area}

We chose the 1,546-ha Kami-Sarobetsu area (elevation: 5-7 m) of the 6,658-ha Sarobetsu Mire (Fujita et al. 2009), Toyotomi town, in northern Hokkaido, Japan, as the study site (Fig. 1). 
Fig. 1: Study area

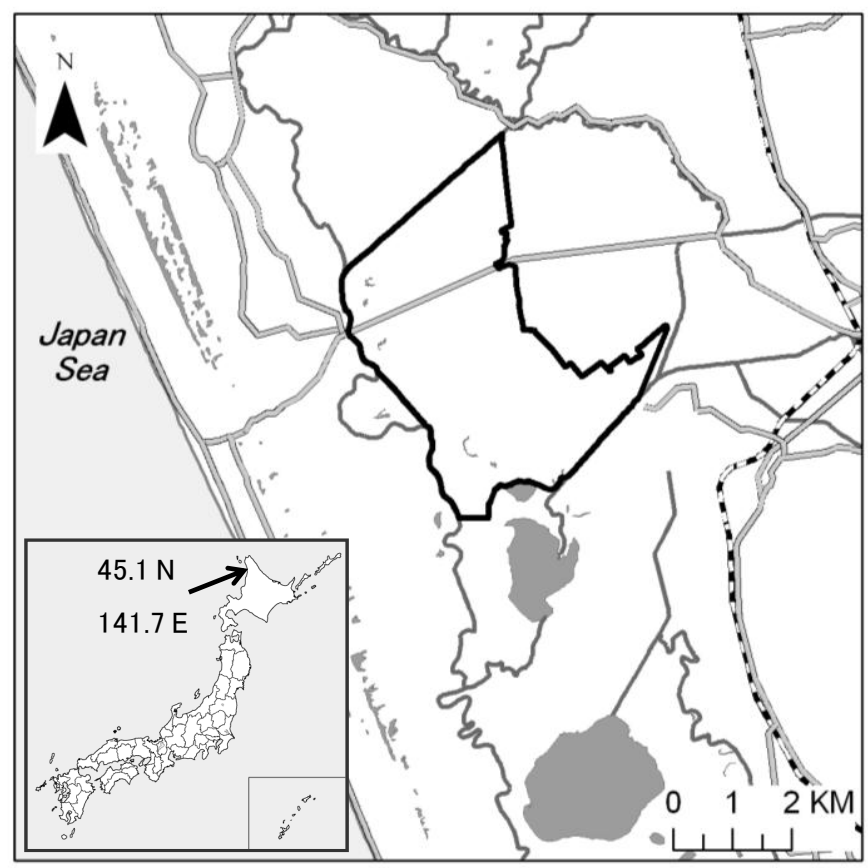

The percentages of land usage for Toyotomi town are $29.9 \%$ farmland, $31.1 \%$ forestry, $21.9 \%$ mire, and $0.6 \%$ residential land (http://www.town.toyotomi.hokkaido.jp/). For the period 1981-2010, the average temperature was $6.1^{\circ} \mathrm{C}$, the average annual rainfall was $1072.5 \mathrm{~mm}$, and the average maximum snow depth was $99 \mathrm{~cm}$. (http://www.jma.go.jp/). The formation of peatlands commenced roughly 4000-5000 years ago, and the current peat depth is about $6 \mathrm{~m}$ (Sakaguchi et al. 1985; Ohira 1995). Sarobetsu mire originally covered about 16,000 ha, and because of conversion for agriculture and peat extraction, ca $70 \%$ of the mire area has been lost (Hotes et al. 2010). The mire contains the largest bog in the country and is designated as a national park and a Ramsar site. The Kami-Sarobetsu area is surrounded by farmland (pasture land), and straightened rivers, drainage ditches and shortcut channels run along the boundary between the mire and farmland; these factors have resulted in low groundwater levels and drying of vegetation (Fujita et al. 2003). Sasa, which grows in a mesic environment, is distributed in the western half of the study site (Fig. 2, 3). It has expanded its distribution every year toward the bog vegetation in the east where Sphagnum moss is dominant; this expansion has threatened the native ecosystem of the area (Takagi et al. 1999; Ito and Wolejko 1990). Although the Japanese Ministry of the Environment and the Hokkaido Regional Development Bureau are (among other measures) implementing measures to mitigate for the negative effects of draining ditches, effective assessment of and countermeasures against Sasa expansion in the inner mire area have not been undertaken. In this study, the continuous frontlines of Sasa in the central area of the Kami-Sarobetsu mire were targeted. 
Fig. 2: Dwarf bamboo (Sasa palmata)

(Dense coverage is $90 \%$ here)

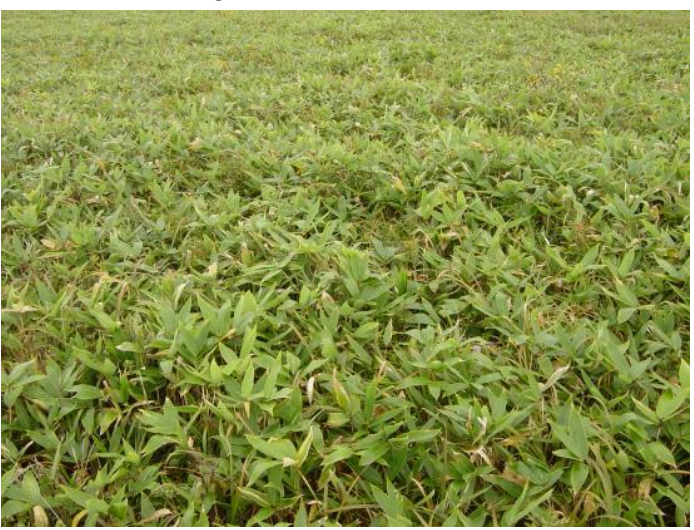

(Kami-Sarobetsu area: by Masayuki TAKADA)

Fig. 3: Sasa flontline

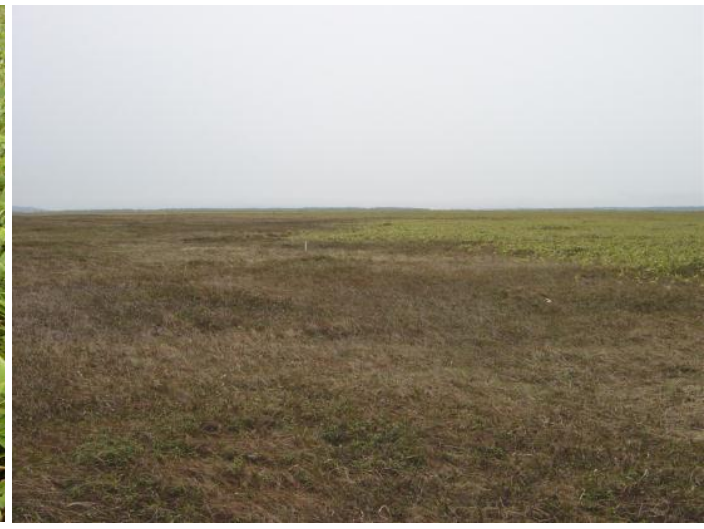

\section{Parameter of Sasa expansion}

Fujita et al. (2003) reported Sasa expansion in the study area. They analyzed aerial photographs taken in 1977 and 2000 to determine the Sasa frontlines, which were then mapped using GIS. These data were used to determine the area expanded by Sasa during the past 23 years (Fig. 4).

\section{Fig. 4 Sasa frontline in the study area}

(Gray line: 1977, Black line: 2000, both from aerial photographs)

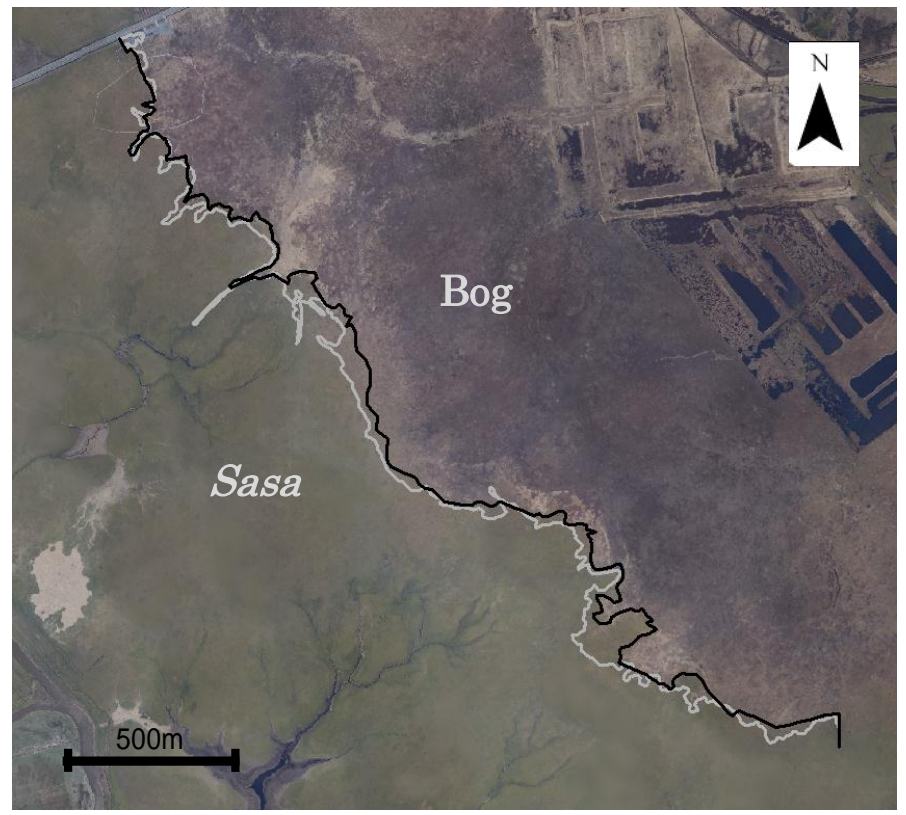




\section{CREATION OF GEOGRAPHICAL PARAMETERS}

To analyze the factors that influence Sasa expansion on a landscape scale, distribution maps associated with topography, hydrology, vegetation and soil are necessary; therefore, using remote sensing and GIS data, geographical data was created for each environmental factor by using the following methods:

\section{Topography}

Several parameters were created using airborne LiDAR data (Ministry of the Environment and AeroAsahi, 2003.5.20; beam divergence: $0.2 \mathrm{~m} \mathrm{rad}$; footprint: $0.18 \mathrm{~m}$; data resolution (grid size): $1 \mathrm{~m}$ ). The elevation was set as the minimum value within the 3 $\mathrm{m} \times 3 \mathrm{~m}$ area around a grid, and the ground surface gradient was calculated from elevation and set as the average value in the $10 \mathrm{~m} \times 10 \mathrm{~m}$ area around a grid. Furthermore, the amount of ground subsidence that occurred in the past 50 years was determined by subtracting the current elevation level from the past elevation level that was determined from the 50-cm-interval contour map created in 1956 (Hokkaido Regional Development Bureau 1963).

\section{Hydrology}

The catchment area map was created by determining the direction of water flow from the gradient of each grid $(1 \mathrm{~m})$ in the elevation data and then calculating the number of grids located upstream of each grid. ArcGIS 9.2 (Flow accumulation tool) was used for this purpose. This parameter gives information about the catchment volume.

In addition, GIS data of natural ditches and abandoned channels were created by referring to the map obtained from Agricultural Engineering Consultants Association (2003). Both landforms are unique to this area; the natural ditches spread out in a tree-like shape toward a river flowing in the west, and the abandoned channels are the remnants of former rivers and are located in the centre. Both are believed to play an important role in water dynamics, including discharge from the mire (Agricultural Engineering Consultants Association 2003).

\section{Vegetation}

Using the airborne LiDAR data, the vegetation heights were estimated. Since the LiDAR data used in this study were expressed by a digital surface model (DSM), for a range of 10 $\mathrm{m} \times 10 \mathrm{~m}$, the distance to the land surface was considered as the lowest value, the distance to the average vegetation height was considered as the average value, and the difference between these two values was considered as an indicator of the average vegetation height. These data were then validated by correlating them with the ground-truth data (72 points).

Furthermore, using satellite images (ALOS/AVNIR-2, 2007.10.5; pointing angle: $0^{\circ}$; cloud cover: 0-2\%; descending) and ground-truth data from 125 points, maps of 6 vegetation classes (sphagnum, sedge-sphagnum, sedge, dwarf bamboo-sedge, dwarf bamboo, and reed) were created by discriminant analysis performed using Mahalanobis' generalized distance. Training error in the discriminant analysis conducted on the basis of data obtained from 125 points was calculated. In order to validate accuracy, test error based on the ground-truth data obtained from 45 other points was calculated.

\section{Soil}

Using the data obtained by satellite SAR (ALOS/PALSAR, 18 images acquired between 2006.3.21 and 2007.10.26; off-nadir angle: 21.5-50.8; level: 1.5) and ground-truth data 
obtained at 33 points, the properties of surface soil (bulk density $\left[\mathrm{g} \mathrm{cm}^{-3}\right]$, carbon content $[\mathrm{g}$ $\mathrm{cm}^{-3}$ ], and ignition loss [organic matter content: wt \%]) were estimated by multiple linear regression analysis (Takada et al. 2009). The gradient, vegetation height, NDVI (normalized difference vegetation index; calculated using data obtained from ALOS/AVNIR-2), and roughness (as measured by the standard deviation within the $10 \mathrm{~m} \times$ $10 \mathrm{~m}$ grids of the airborne LiDAR data) were used as explanatory variables. An analysis of 18 APLOS/PALSAR images was performed, and the bulk density on 15 October 2007, volumetric carbon content on 21 April 2007, and the ignition loss on 26 October 2007 were selected to compose a map, owing to their high significance and multiple correlation coefficients. In order to validate accuracy, the estimates were compared with ground-truth data obtained from 47 points.

\section{ANALYSIS OF SASA EXPANSION FACTORS}

\section{Variation in each factor on the Sasa frontlines}

To analyze how each environmental factor changes on the Sasa frontlines, a value was determined for each environmental factor at 10-m intervals for the Sasa frontlines in the year 2000. In the case of natural ditches and abandoned channels, the nearest distances were calculated.

\section{Estimation of expansion factors}

A field survey by Takahashi (2003) and a GPS survey by Tani et al. (2006) confirm that the frontline of dwarf bamboo is expanding in its entirety in the northeast direction (Fig.4). First, on the basis of these findings, the average direction from the starting to the end point of this frontline was calculated using the linear directional mean tool of ArcGIS. Next, with the northern point of origin as the starting point, the frontline was divided into $100-\mathrm{m}$ interval slices, perpendicular to the average direction (Fig. 5). The Sasa expansion area within each sliced zone was used as a criterion variable. Next, we identified an analysis zone in the form of a square $(\mathrm{N}=30)$ of $100 \mathrm{~m} \times 100 \mathrm{~m}$ at the centre of each dwarf-bambooexpansion area (Fig.5). The direction of the square was set to be that obtained by connecting the points at which the two dwarf-bamboo frontlines (pertaining to two periods) intersect with each sliced line; these squares were used as areas for analysis. The average value and variation (standard deviation) in the elevation, gradient, and catchment area, as well as the average value of the vegetation height, amount of ground subsidence, and 3 soil factors were obtained and used as explanatory variables. In the case of natural ditches and abandoned channels, the nearest distances were used.

Multiple linear regression analysis was performed on these data in order to identify the factor that contributes to Sasa expansion. 


\section{Fig. 5: Slice zone and squares for analysis}

(Slice zone: divided at 100-m intervals, Squares: $100 \mathrm{~m} \times 100 \mathrm{~m}$ at each sliced zone)

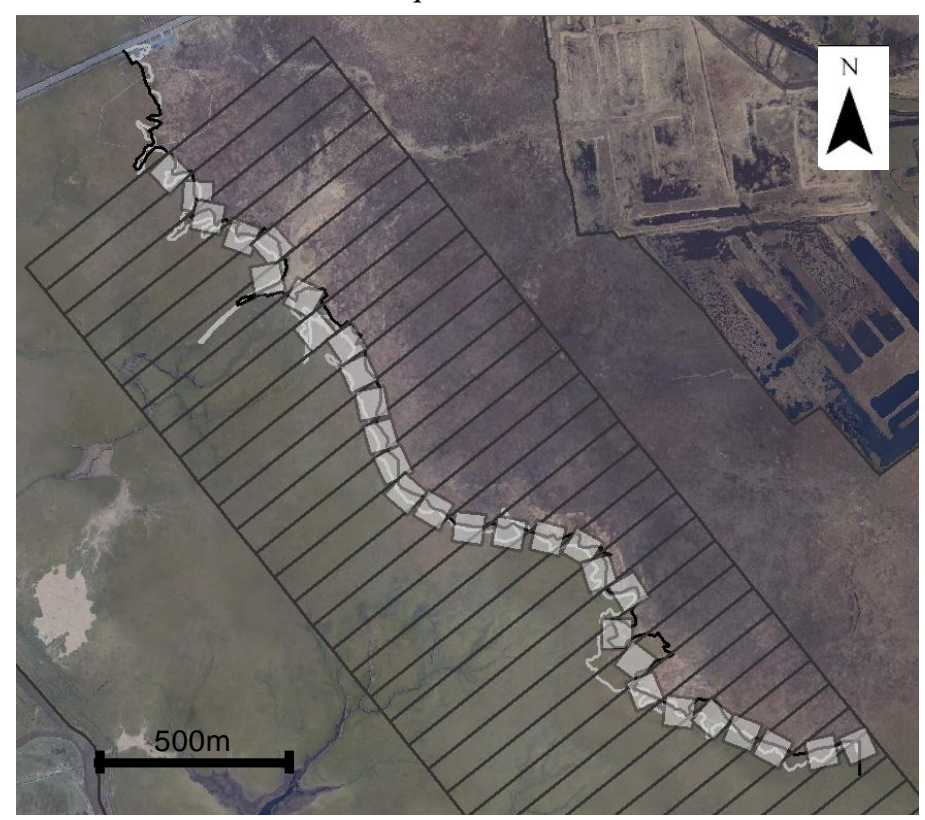

(Gray line: 1977, Black line: 2000, both from aerial photographs)

\section{Characteristics of the vegetation near Sasa frontlines}

Using the vegetation maps, the fraction of the area was calculated for each of six vegetation classes within the aforementioned analysis areas, and the characteristics of the vegetation near the Sasa frontlines were analyzed by quantification theory type I. This theory is based on a multiple regression analysis method that uses a dummy variable in order to analyze qualitative data (not numerical) such as degree, status, presence/ absence, and YES/ NO (Hayashi 1954).

\section{RESULTS AND DISCUSSION}

\section{Mapping the geographical parameters and validating the maps}

Figure 6 shows several maps created for different environmental factors as examples. The correlation coefficient between the estimated vegetation heights and the corresponding ground-truth values was 0.74 (contribution rate: 0.55 ); this indicates that the estimates reflect the actual values. Furthermore, on the basis of the vegetation maps, the training error was $16.8 \%$ and test error was $22.2 \%$ for separately obtained data. When calculated from the variance, the ratios of soil factors within the $95 \%$ reliability range were $100 \%$ for bulk density, $97 \%$ for volumetric carbon content, and $98 \%$ for ignition loss, respectively. 


\section{Fig. 6: Distribution maps of environmental factors (examples)}

$((1)(2)(4)$ : calculated from airborne LiDAR, (5)(6): calculated from satellite images,

(4)(5)(6): verified by ground-truth sampling)

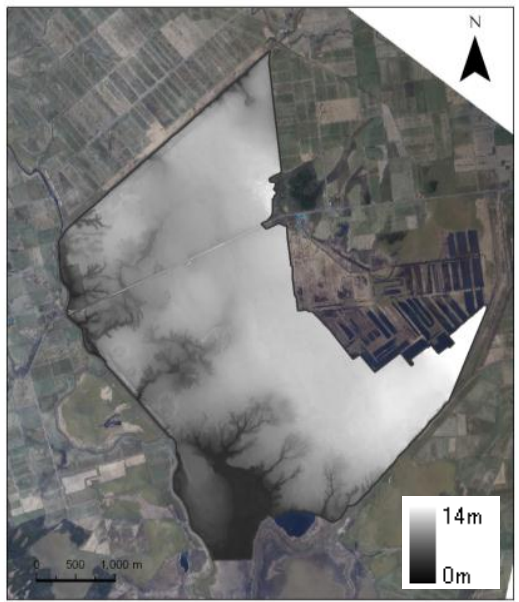

(1) Elevation

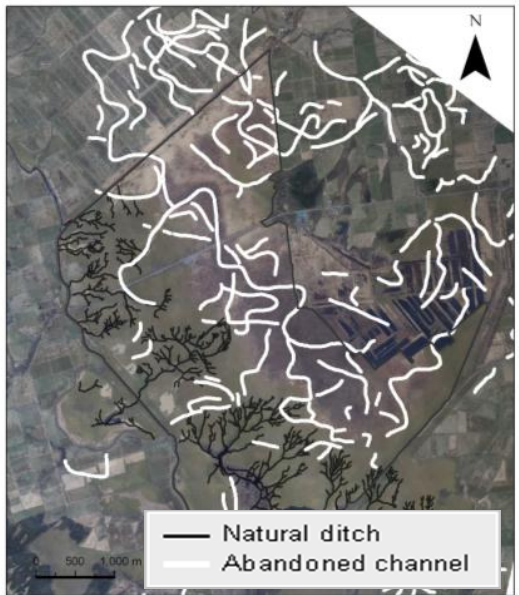

(3) Natural ditch and abandoned channel

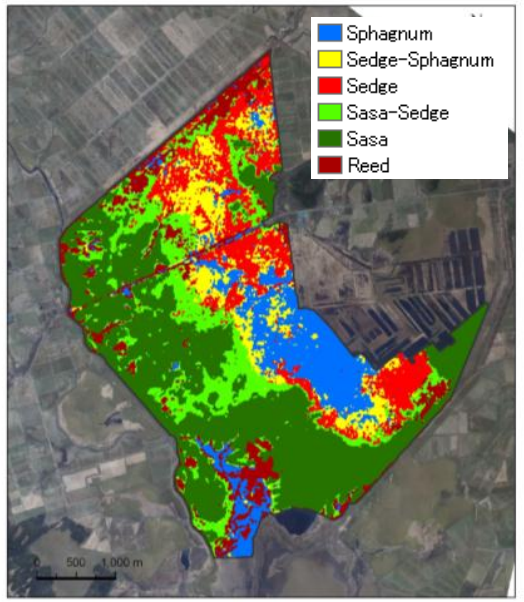

(5)Vegetation class

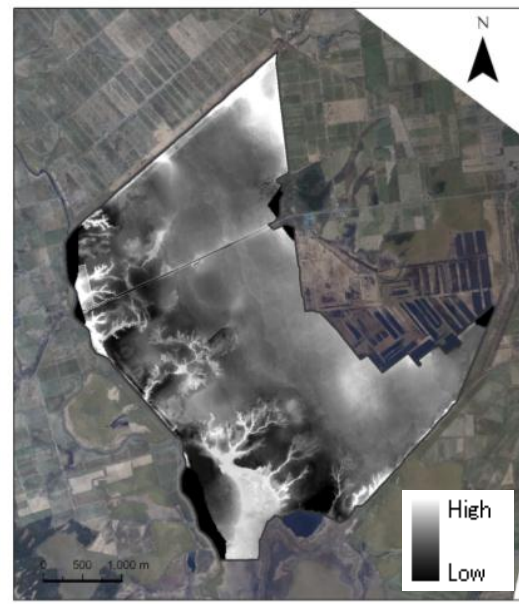

(2) Ground subsidence

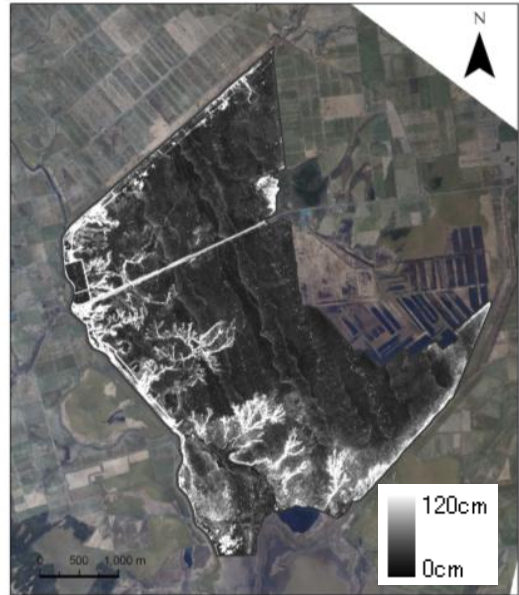

(4) Vegetation height

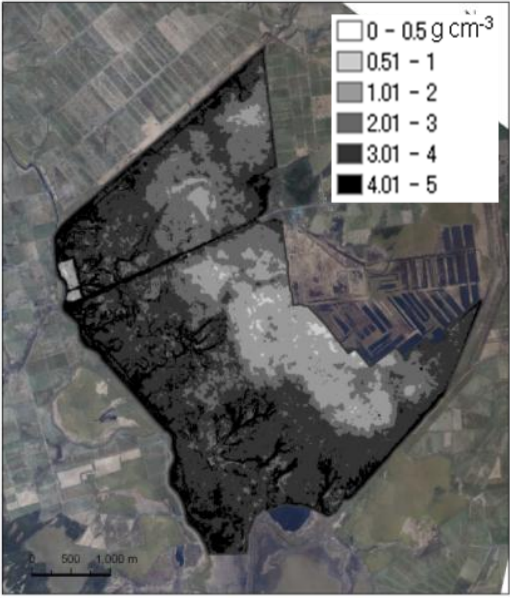

(6) Carbon content 
Journal of Landscape Ecology (2012), Vol: 5 / No. 1.

\section{Analysis of Sasa expansion factors}

Fig. 7: Variation in environmental factors on the Sasa frontlines

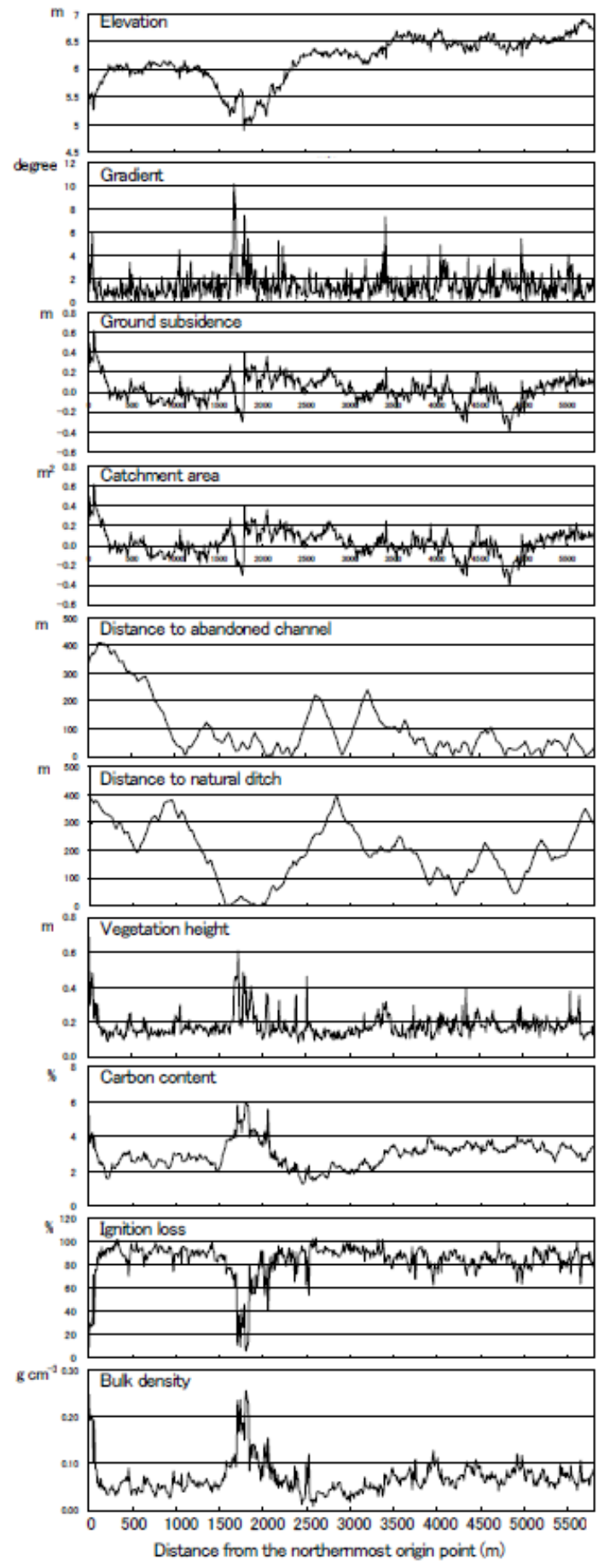


Figure 7 shows the variation in each environmental factor on the Sasa frontlines. In the area located at 1,500-2,000 $\mathrm{m}$ from the northernmost origin point, natural ditches extend to the central area of the mire, and the variation in all factors was large. In the southern area at the 3,500-m point or further from the origin, the overall variations were smaller than those in the northern area. This may be because the process of mire formation in the northern area differs from that in the southern area (Ohira 1995). That is to say, the southern region is contaminated with silt/clay from flooding. The variation between the origin and the $250-\mathrm{m}$ point is due to the strong influence of ground subsidence caused by roads and buildings. The carbon content is converted on a per-volume basis, and because of the fact that the soil density increases with soil decomposition, it has an inverse relationship with the ignition loss.

\section{Estimation of expansion factors}

Multiple linear regression analysis was performed for all combinations of the explanatory variables. As a result of excluding 2 data points, which had extremely large estimated residuals, a model with high significance and correlation was obtained. Figure 8 is a histogram of the frequencies of the selected explanatory variables for the 20 cases corresponding to the highest significance levels (lowest $p$ values). For the 5 cases corresponding to the highest multiple correlation coefficients, the level of significance ( $p$ value) and standard partial regression coefficient are presented for each explanatory variable (Table 1).

Table 1: The level of significance ( $p$ value) and standard partial regression coefficient for the 5 cases with the highest multiple correlation coefficients obtained

\begin{tabular}{c|c|c} 
& Standard partial regression coefficient & $p$ Value \\
\hline Distance to natural ditches & $-1.00 \sim-1.03$ & $0.000 \sim 0.001$ \\
Elevation (variation) & $-0.87 \sim-1.06$ & $0.001 \sim 0.003$ \\
Gradient (variation) & $0.79 \sim 1.04$ & $0.003 \sim 0.009$ \\
Ground subsidense & $0.16 \sim 0.17$ & $0.343 \sim 0.380$ \\
Catchment area (variation) & -0.15 & 0.347 \\
Catchment area (average) & $-0.14 \sim-0.15$ & $0.360 \sim 0.391$ \\
Carbon content & $-0.96 \sim-1.58$ & $0.002 \sim 0.005$ \\
Bulk density & $0.40 \sim 0.53$ & $0.278 \sim 0.406$
\end{tabular}

Figure 8 shows that the distance to natural ditches, carbon content of surface soil, and variation in gradient and elevation are the largest contributors. Table 1 shows that the $p$ value of each variable was lower than $1 \%$ in the case of these 4 parameters. On the basis of the analysis of the standard partial regression coefficient, Sasa expansion was found to be negatively correlated with distance to natural ditches, carbon content, and elevation variation and positively correlated with gradient variation. 
Fig. 8: Histogram of the frequencies in absolute number of the selected explanatory variables for the 20 cases with the highest significance levels obtained

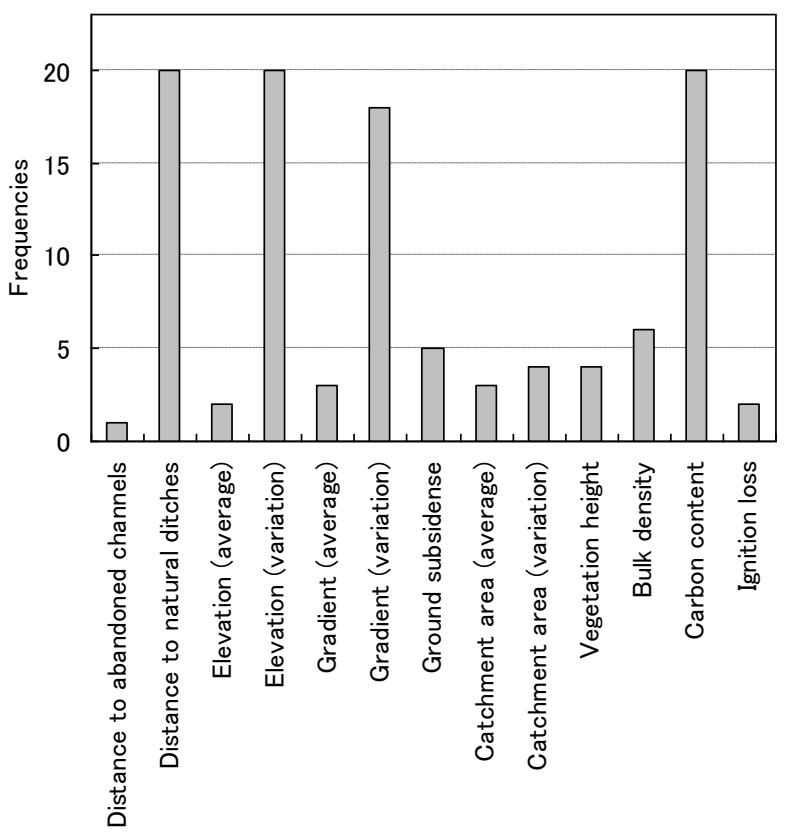

\section{DISCUSSION OF SASA EXPANSION}

These results suggest that Sasa expansion is strongly associated with water movement and soil properties. In particular, the distance to natural ditches, gradient, and elevation are the factors directly associated with water movement, and it is suggested that the decrease in groundwater level caused by water discharge and the supply of oxygen and nutrients through water movement, among other causes, are promoting the propagation of Sasa.

The hydrological factor is characterized by features such as large and short-term fluctuations with respect to precipitation, evapotranspiration, and discharge and its small and long-term fluctuations with respect to topology. It is presumed that the former feature, in addition to the physiology and microenvironment of Sasa, may determine forward and backward movement of Sasa frontlines in the short term, and the latter feature may determine the directivity of Sasa expansion in the long term. Moreover, the carbon content of the soil is considered to be an indirect index which shows that soil properties associates with groundwater level (Ma"kiranta et al. 2009; Laiho 2006).

For these 5 abovementioned cases, the multiple correlation coefficients were between 0.777 and 0.781 , and the contribution rates were between $60 \%$ and $61 \%$. These results indicate that the geographical parameters used in this study can explain approximately $60 \%$ of the Sasa expansion factors. The 2 data points that were excluded from the analysis were recorded in the south of the mire. In the future, the possibility of these factors being related to other factors, such as the formation process of peat and water quality, must be discussed. 


\section{Characteristics of the vegetation near the Sasa frontlines}

Analysis of the characteristics of the vegetation near the Sasa frontlines, based on quantification theory type I, showed that in the case in which the selected variable gave the highest multiple correlation coefficient (0.50), the relationship of the area of Sasa expansion with the area of dwarf bamboo-sedge vegetation was the strongest $(p=0.014)$. This indicates that Sasa propagates along with sedge, and therefore, the sedge vegetation may serve as an indicator of the highest probability of Sasa expansion in the areas near the Sasa frontlines.

\section{CONCLUSIONS}

The factors contributing to Sasa expansion over the past 23 years were estimated using the geographical parameters derived on the basis of remote sensing and GIS data. It was shown that the hydrological factor was the largest contributor to Sasa expansion and might have determined the speed and direction of expansion. Furthermore, it was possible to determine $60 \%$ of the causes of Sasa expansion by using the derived geographical parameters. Expansion of Sasa populations in the mire involves biological and chemical factors that are interrelated in a complex manner, and the relationships among these factors have not yet been elucidated. Traditionally, research on Sasa dynamics in the mire has been conducted in situ in the case of particular sites (for example, Takagi et al. 1999; Takakuwa and Ito 1986). In the future, a landscape-based approach will be combined with a field study in order to possibly identify the causes of Sasa expansion. In this sense, the results confirm the effectiveness of a landscape approach and help to identify geographical factors responsible for Sasa expansion. It is expected that by deriving other geographical parameters (evapotranspiration, formation process, etc.) for use in analysis, the accuracy of the model to Sasa expansion can be higher.

Future changes in the locations of the Sasa frontlines need to be monitored. Sasa communities are a threat to the local bog ecosystem, and it is necessary to develop monitoring methods and countermeasures considering whether Sasa has existed there for a long time, its distribution is gradually expanding, or its distribution has rapidly expanded in recent years because of human impact. In this context, it is important to adopt a more comprehensive and integrated landscape approach based on human activity and land use. We hope that our findings will lead to subsequent studies and thereby contribute to more adequate conservation and management of the vegetation of valuable wetland ecosystems.

\section{ACKNOWLEDGEMENTS}

This research was supported by the Environment Research and Technology Development Fund (D-0908 and S9) of the Ministry of the Environment, Japan, and a Grant-in-Aid for Scientific Research (No.20-241002) of the Japan Society for the Promotion of Science.

\section{REFERENCES}

Agricultural engineering consultants association (2003). The formation map in Sarobetsu Peatland. (in Japanese)

Fujita, H. (2007). Wetland ecosystems, its conservation and restoration in Hokkaido. Global Environment, 12: 7-20. (in Japanese) 
Fujita, H., Igarashi, Y., Hotes, S., Takada, M., Inoue, T. \& Kaneko, M. (2009). An inventory of the mires of Hokkaido, Japan-their development, classification, decline, and conservation. Plant Ecology, 200: 9-36.

Fujita, H., Kanoh, S. \& Imai, H. (2003). The time series mapping and detecting area changed of dwarf bamboo in Kami-Sarobetsu Mire. Bull Bot Garden, Hokkaido University, 3: 3-50. (in Japanese)

Gorham, E. (1991). Northern peatlands: Role in the carbon cycle and probable responses to climatic warming. Ecological Applications, 1: 182-195.

Hayashi, C. (1954). Application of quantification theory. Research Report of the Institute of Statistical Mathematics, 2(1): p11-30. (in Japanese)

Hobbs, R.J., Humphrise, S.E. (1995). An integrated approach to the ecology and management of plant invasions. Conservation Biology, 9: 761-770.

Hokkaido development agency, 1963: The contour map of peat depth in Sarobetsu Peatland. (in Japanese)

Hotes, S., Grootjans, A.P., Takahashi, H., Ekschmitt, K. \& Poschlod, P. (2010). Resilience and alternative equilibria in a mire plant community after experimental disturbance by volcanic ash. Oikos, 119: 952-963.

Ito, H., Hino, T. (2007). Dwarf bamboo as an ecological filter for forest regeneration. Ecological Research, 22: 706-711.

Ito, K., Wolejko, L. (1990). A conservational review of Sarobetsu Mire, northern Hokkaido. Environmental Science, Hokkaido University, 13: 75-92.

Kellner, E., Halldin, S. (2002). Water budget and surface-layer water storage in a Sphagnum bog in central Sweden. Hydrological Processes, 16: 87-103.

Laiho, R. (2006). Decomposition in peatlands: Reconciling seemingly contrasting results on the impacts of lowered water levels. Soil Biology and Biochemistry, 38(8): 2011-2024.

Mäkiranta, P., Laiho, R., Fritze, H., Hytönen, J., Laine, J. \& Minkkinen, K. (2009). Indirect regulation of heterotrophic peat soil respiration by water level via microbial community structure and temperature sensitivity. Soil Biology and Biochemistry, 41(4): 695-703.

Maltby, E., Immirzi, C.P. (1993). Carbon dynamics in peatlands and other wetland soils regional and global perspectives. Chemosphere, 27: 999-1023.

Narukawa, Y., Yamamoto, S. (2002). Effects of dwarf bamboo (Sasa sp.) and forest floor microsites on conifer seedling recruitment in a subalpine forest, Japan. Forest Ecology and Management, 163: 61-70.

Ohira, A. (1995). Holocene Evolution of Peatland and Paleoenvironmental Changes in the Sarobetsu Lowland, Hokkaido, Northern Japan. Geographical Review of Japan, 68A-10: 695-712. (in Japanese with English summary)

Petrone, R.M., Price, J.S., Carey, S.K. \& Waddington, J.M. (2004). Statistical characterization of the spatial variability of soil moisture in a cutover peatland. Hydrological Processes, 18: 41-52.

Pfadenhauer, J., Schneekloth, H., Schneider, R. \& Schneider, S. (1993). Mire Distribution. In A.L. Heathwaite \& K. H. Göttlich (Eds.): Mires: Process, Exploitation and Conservation. (pp. 77-121). Wiley \& Sons

Rydin, H., Jeglum, J. (2006). The biology of peatlands, 1st edn. Oxford University Press, Oxford. 
Sakaguchi, Y., Kashima, K. \& Matsubara, A. (1985). Holocene marine deposits in Hokkaido and their sedimentary environments. Bull Dept Geogr Univ Tokyo, 17:1-17.

Suyama, Y., Obayashi, K. \& Hayashi, I. (2000). Clonal structure in a dwarf bamboo (sasa senanensis) population inferred from amplified fragment length polymorphism (AFLP) fingerprints. Molecular Ecology, 9: 901-906.

Takada, M., Mishima, Y. \& Natsume, S. (2009). Estimation of surface soil properties in peatland using ALOS/PALSAR. Landscape and Ecological Engineering, 5 (1): 45-58.

Takagi, K., Tsuboya, T., Takahashi, H. \& Inoue, T. (1999). Effect of the invasion of vascular plants on heat and water balance in the Sarobetsu mire, northern Japan. Wetlands, 19: 246-254.

Takahashi, H. (2003). Microclimate and moving of Sasa frontline in Sarobetsu mire. The third research report on conservation of Sarobetsu mire by Ministry of the Environment: 110. (in Japanese)

Takakuwa, J., Ito, K. (1986). Ecological aspect of Sasa in Mires. Bull Environmental Science, Hokkaido University, 2: 47-65. (in Japanese with English summary)

Tani, H., Guo, Y., Takada, M., Takahashi, H. \& Wang, X. (2006). Study on invasion of Sasa sp. in Sarobetsu mire by satellite data. Papers on Environmental Information Science 20: 361-366. (in Japanese with English summary) 